\title{
A Study on the Effects of Treatment for Upper Protrusion in Adult Females by the Edgewise Method
}

\author{
by
}

\author{
Susumu SHIMABUKURO
}

\section{Introduction}

It is generally maintained that orthodontic treatment proves to be the most effective when it is performed according to the growth and development of individuals. In most cases, so far, treatment has been performed when the growth of the gnatho-facial region is most active.

With the advance of restorative treatment in recent years plastic surgery for cleft palates[1,2] as well as highly advanced ostectomies for gnathic anomalies[3,4] have gradually come to be performed in real earnest. This, is effect, increases the opportunity for performing orthodontic treatment both pre- and post-operatively. A considerable number of these cases involve adult patients in whom growth and development are thought to have been completed.

So far, however, orthodontic treatment has been performed during the early stages of growth and development of the patient. As a result, it has been difficult to evaluate what part has resulted from natural growth and development and what part has been improved by orthodontic treatment. To this day, only TACOGNA[5] is known to have reported on the differentiation between these two and by no means does his report provide sufficient information concerning orthodontic treatment for adults.

The author, in this study, observed the cephalograms of orthodontically treated female patients in whom the growth and development of their gnatho-facial regions were thought to have been completed. The author's interesting findings on the regions and amounts of change between the pre- and post-treatment phases are as follows.

\section{Materials and Methods}

\subsection{Materials}

For this study the cephalograms taken both pre- and post-operatively of 20 female patients with upper protrusion were observed. These patients had been treated by the edgewise method at the Department of Orthodontics, Nihon University Dental Hospital. They had been diagnosed as cases of Angle Class II Division 1, having an overjet larger than $5 \mathrm{~mm}$. The subjects were over 17 years of age and had not shown evidence of growth and development in their gnatho-facial bones according to the criteria by MeLson[8] and AsAi[9]. Their mean age before the pro-

*島袋進: Department of Orthodontics, Nihon University School of Dentistry. (Director: Prof. Masatoshi ARITA). 


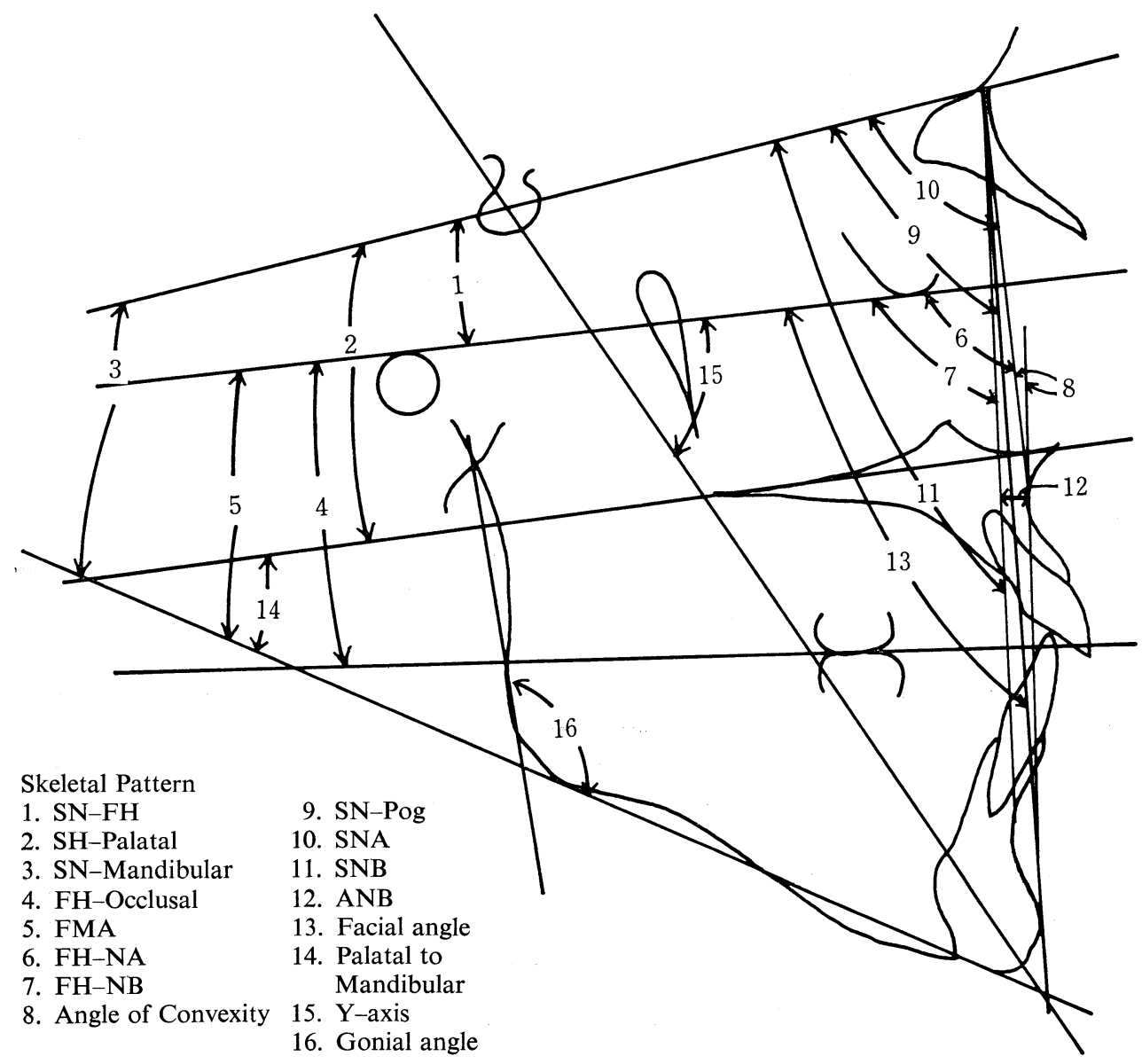

Fig. 1 Angulation measurement

cedure was 18 years and 3 months with an average overjet of $7.07 \mathrm{~mm}$. Their mean treatment period was 2 years and 7 months.

\subsection{Methods}

As shown in Figs. 1 and 2 the pre- and post-operative cephalograms of the above-mentioned 20 subjects were used for a series of measurements and comparisons. The analytical methods of both Downs[10] and NorTHWeSTERn[11,12] were employed for this purpose.

\section{Results and Discussion}

The results are shown in Tables 1 to 5 and Figs. 3 to 15. Changes in denture pattern were most prominent (Table 2 and Fig. 3).

Besides the data concerning the post-operative denture and skeletal patterns 


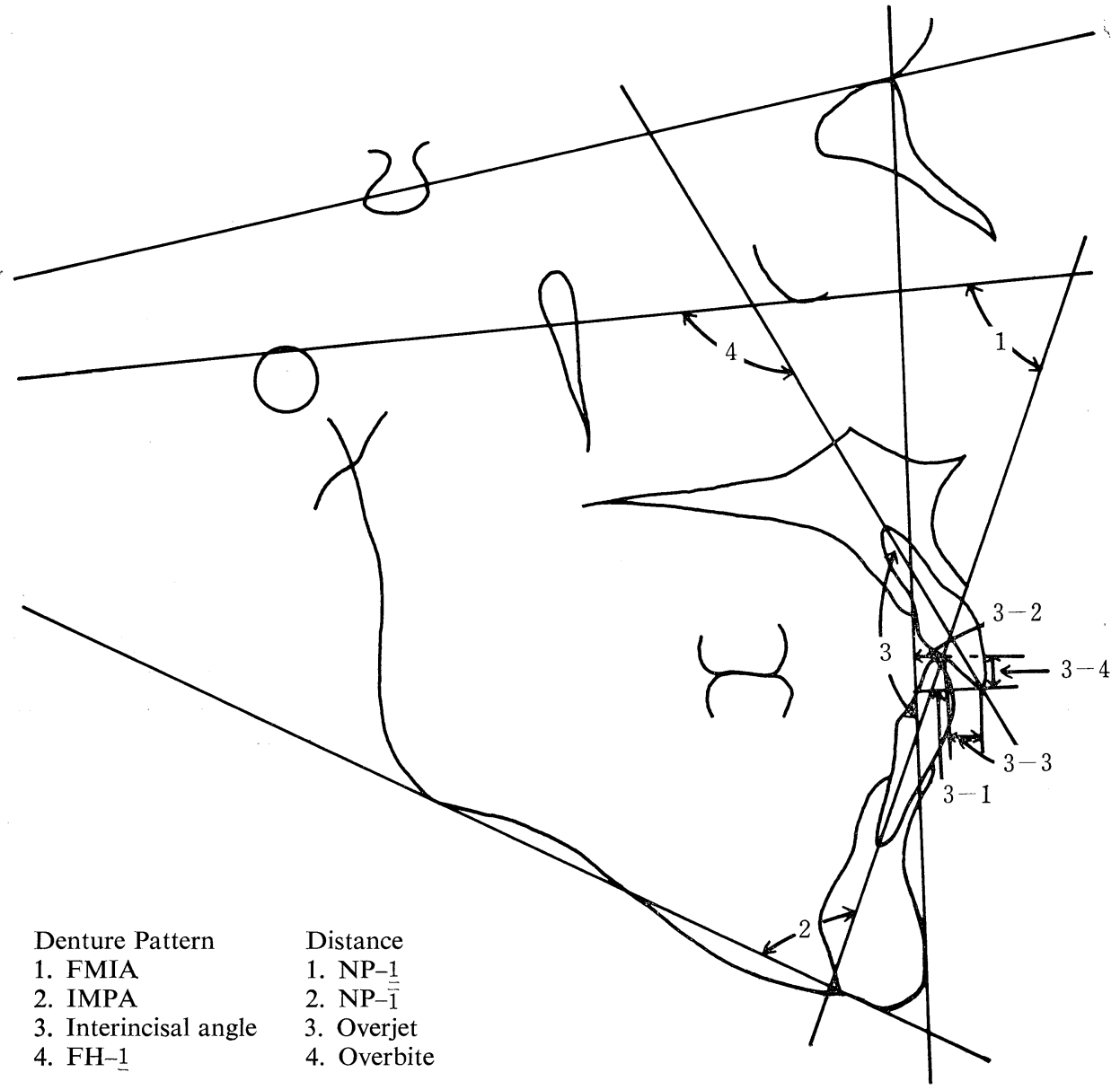

Fig. 2 Angulation and distance measurements

the standard data representing subjects of the same age are listed in Table 2 for comparative purposes[13].

As already mentioned above, it is generally asserted that orthodontic treatment is most effective when it is given according to the growth and development of individuals. Thus, in most cases it is performed when the growth of the gnatho-facial region is most active.

In recent years there has been an increase in the number of cases in which orthodontic treatment was performed before and after plastic surgery for a cleft palate or an ostectomy for gnathic anomalies[3,4].

Most of these cases involve adult patients whose growth and development have almost ceased. In performing effective orthodontic treatment for adult patients there are many points yet to be solved with respect to such fundamental issues as, for example, how to correct a cleft palate with a wide variety of malposed teeth[1,2], 
Table 1 Changes in angle measurements

\begin{tabular}{|c|c|c|c|c|c|c|c|}
\hline & Mean & S.D. & Change & & Mean & S.D. & Change \\
\hline \multirow[b]{2}{*}{$\mathrm{S}-\mathrm{N}$ to $\mathrm{FH}$} & 7.16 & 3.52 & \multirow{2}{*}{-1.010} & \multirow{2}{*}{$Y$-axis } & 65.31 & 4. 12 & \multirow{2}{*}{-0.30} \\
\hline & 7.15 & 3.29 & & & 65.01 & 4.36 & \\
\hline \multirow{2}{*}{ S-N to Palatal } & 8.52 & 2.97 & \multirow[b]{2}{*}{0.05} & \multirow{2}{*}{ Gonial angle } & 125.22 & 6.21 & \multirow{2}{*}{-0.11} \\
\hline & 8.57 & 3.43 & & & 125.11 & 6.40 & \\
\hline \multirow[b]{2}{*}{ S-N to Mandibular } & 38.09 & 6.23 & \multirow{2}{*}{-0.15} & \multirow{2}{*}{ ANB } & 3.79 & 2.35 & \multirow{2}{*}{0.40} \\
\hline & 37.94 & 6.04 & & & 4. 19 & 3.42 & \\
\hline \multirow{2}{*}{ FH to Occlusal } & 8.22 & 4.09 & \multirow{2}{*}{2.57} & \multirow{2}{*}{$\begin{array}{l}\text { Palatal to } \\
\text { Mandibular }\end{array}$} & 29.65 & 5.89 & \multirow{2}{*}{-0.02} \\
\hline & 10.79 & 4.00 & & & 29.63 & 6.48 & \\
\hline \multirow{2}{*}{ FH to Mandibular } & 31.07 & 5.95 & \multirow{2}{*}{-0.56} & \multirow{2}{*}{ FH to 1} & 121.50 & 7.38 & \multirow{2}{*}{-17.15} \\
\hline & 30.51 & 6.13 & & & 104.35 & 9.40 & \\
\hline \multirow[b]{2}{*}{ SNA } & 80.67 & 3.87 & \multirow[b]{2}{*}{0.16} & \multirow{2}{*}{ FH to 1} & 57.45 & 4.81 & \multirow[b]{2}{*}{ 4. 71} \\
\hline & 80.83 & 3.59 & & & 62.16 & 6.58 & \\
\hline \multirow[b]{2}{*}{ FH to NA } & 87.82 & 2.90 & \multirow{2}{*}{0.25} & \multirow{2}{*}{1 to 1} & 116.57 & 5.95 & \multirow{2}{*}{ 19. 34} \\
\hline & 88.07 & 3.44 & & & 135.91 & 5.76 & \\
\hline \multirow{2}{*}{ Convexity } & 7.56 & 5.25 & \multirow{2}{*}{-1.20} & \multirow{2}{*}{ Mandibular to 1} & 91.63 & 6.62 & \multirow{2}{*}{-4.67} \\
\hline & 6.36 & 6.61 & & & 86.96 & 6.40 & \\
\hline \multirow{2}{*}{ SNB } & 77.00 & 3.02 & 028 & NP to $1(\mathrm{~mm})$ & 15.09 & 3.64 & \\
\hline & 77.28 & 2.67 & 0.28 & NP to $1(\mathrm{~mm})$ & 8.90 & 3.28 & -6.19 \\
\hline & 77.30 & 2.93 & & & 8.13 & 2.84 & \\
\hline SN Fog & 77.84 & 2.70 & 0.54 & $\mathrm{NP}$ to $1(\mathrm{~mm})$ & 4.83 & 3.59 & -3.30 \\
\hline & 84.02 & 2.62 & & & 7.07 & 1.63 & \\
\hline FH to NB & 84.48 & 2.79 & 0.46 & Overjet (mm) & 3.08 & 0.97 & -3.99 \\
\hline & 54.39 & 2.97 & & & 4.42 & 1.42 & \\
\hline Facial angle & 54.96 & 3.19 & 0.57 & Overbite (mm) & 3.78 & 0.76 & -0.64 \\
\hline
\end{tabular}

Note: Upper columns refer to pre-treatment and lower columns to post-treatment conditions

whether or not to perform an ostectomy or whether or not orthodontic treatment will suffice. Pertinent information now available is not necessarily sufficient.

From this point of view the author conducted the above-mentioned measurements on adult females who had received orthodontic treatment. The results are considered to serve as appropriate criteria for evaluating the effects of treatment for upper protrusions. The following points of measurement were used for examination. (1) Changes in the skeletal pattern (Table 1, Figs. 3 and 4)

1. SNA

The mean value before treatment was $80.67^{\circ}( \pm 3.87)$, whereas after treatment it was $80.83^{\circ}( \pm 3.59)$. Almost no change was observed in the anteroposterior direction of the maxilla.

SAKAмото[14], in his quantitative measurements of the facial growth of Japanese using sella turcica as an indication, observed that there was a certain anterior growth of the $\mathrm{N}$ and $\mathrm{A}$ points about 7 to 10 years of age. However, IIzUKA[15] hardly noted any change during this period. He claims that the growth of the maxillary facial region reaches approximately $90 \%$ of that of an adult by the age of about 5 .

The results obtained by the author also suggest almost no influence from the effects of orthodontic treatment. 


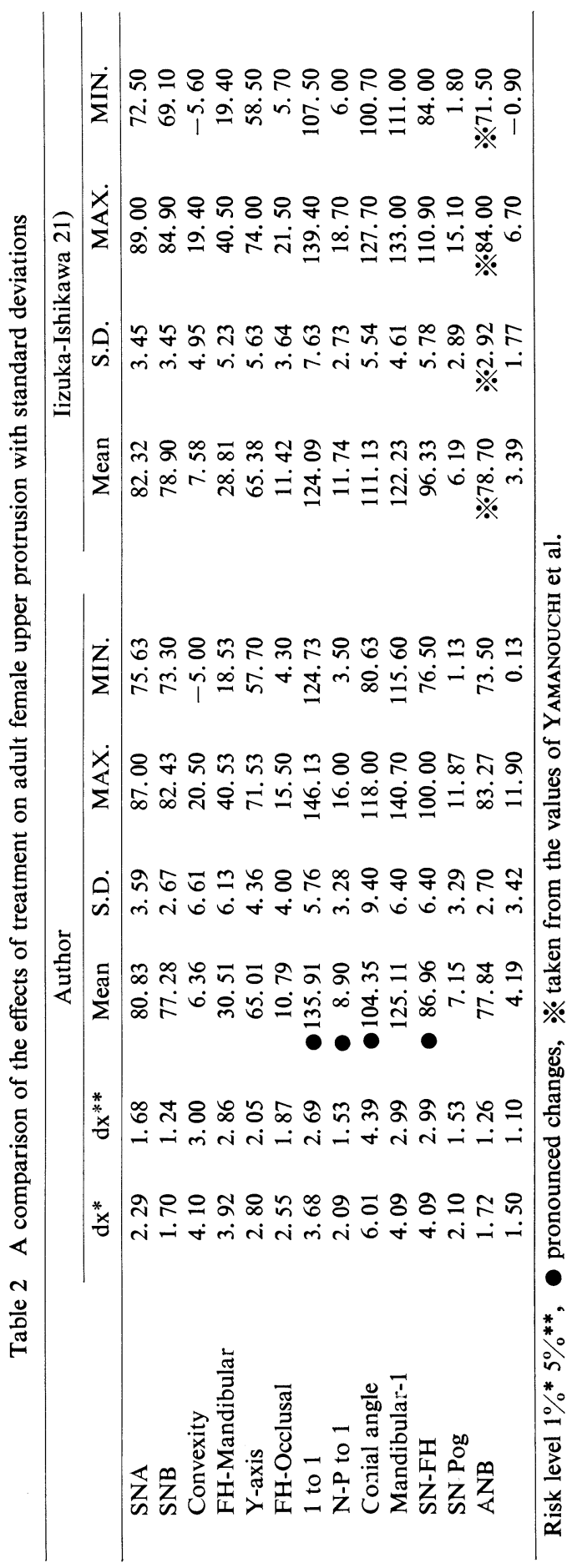


Table 3 Changes in the $\underline{1}$ to $\overline{1}$

\begin{tabular}{lrrrr}
\hline & Mean & S.D. & MAX. & MIN \\
\hline Pre-treatment & 116.57 & 5.95 & 130.20 & 104.10 \\
Post-treatment & 135.91 & 5.76 & 146.13 & 124.73 \\
Difference & 19.34 & & 36.10 & 9.00 \\
\hline
\end{tabular}

Table 4 Changes in the NP to $\underline{1}$, NP to $\overline{1}$

\begin{tabular}{rlrrrr}
\hline & & Mean & S.D. & MAX. & \multicolumn{1}{c}{ MIN. } \\
\hline \multirow{3}{*}{ NP to 1} & Pre-treatment & 15.09 & 3.64 & 20.50 & 7.50 \\
& Post-treatment & 8.90 & 3.28 & 16.00 & 3.50 \\
& Difference & -6.19 & & -11.20 & -2.00 \\
\hline \multirow{3}{*}{ NP to $\overline{1} 1$} & Pre-treatment & 8.13 & 2.84 & 13.00 & 3.20 \\
& Post-treatment & 4.83 & 3.59 & 12.30 & -2.00 \\
& Difference & -3.30 & & -7.50 & 2.50 \\
\hline
\end{tabular}

Table 5 Changes in overjet and overbite

\begin{tabular}{lrrrrr}
\hline & \multicolumn{2}{c}{ Overjet } & & \multicolumn{2}{c}{ Overbite } \\
\cline { 2 - 3 } \cline { 5 - 6 } & Mean & S.D. & & Mean & S.D. \\
\hline Pre-treatment & 7.07 & 1.63 & & 4.42 & 1.42 \\
Post-treatment & 3.08 & 0.97 & & 3.78 & 0.76 \\
Difference & -3.99 & & & -0.64 & \\
\hline
\end{tabular}

\section{SNB}

The mean value before treatment was $77.00^{\circ}( \pm 3.02)$ and after treatment it was $77.28^{\circ}( \pm 2.67)$, showing no noteworthy difference. Individually, however, 13 out of the 20 cases under study had almost no change, whereas a decrease occurred in 2 cases and as many as 5 cases gave evidence of an increase. This is clearly indicated in the histograms that show post-treatment changes in the SNB (Fig. 5).

According to IrzuKa[15] there is no apparent change in the SNB during Hellman's Dental Ages III A and III C. In this respect, however, the 5 cases of increase and the 2 cases of decrease may have resulted from orthodontic treatment, but to clear up these points further study of many more such cases will be required.

3. ANB

The mean value before treatment was $3.79^{\circ}( \pm 7.35)$ and after treatment it was $4.19^{\circ}( \pm 3.42)$, showing no notable change in the anteroposterior direction of the maxilla or the mandible. Individually, however, out of the 20 cases 10 had almost no change, 6 cases showed evidence of decrease and an increase took place in the remaining 4 cases. This is clear from the histograms that show post-treatment changes in the ANB (Fig. 6).

It is desirable for the ANB, indicative of the anteroposterior relationship of the maxilla and mandible, to decrease as a result of treatment for upper protrusion. Responsible for the favorable results in the 6 cases may be the forward movement of Point A from labial root torque together with a forward movement of the mandible.

4. Facial angle

The mean value before treatment was $54.39^{\circ}( \pm 2.97)$ and after treatment it was 


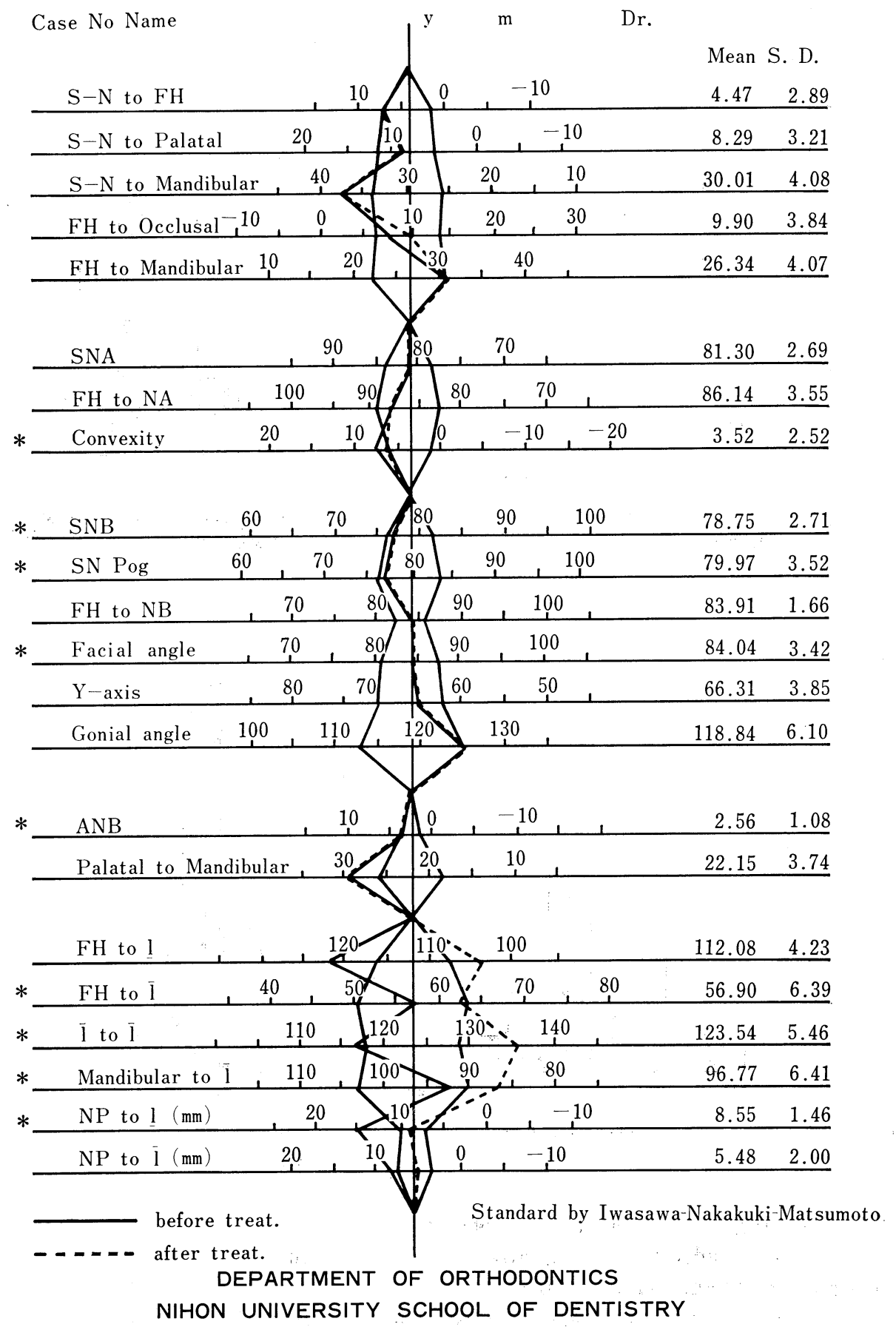

Fig. 3 Roentgenocephalometric analysis 


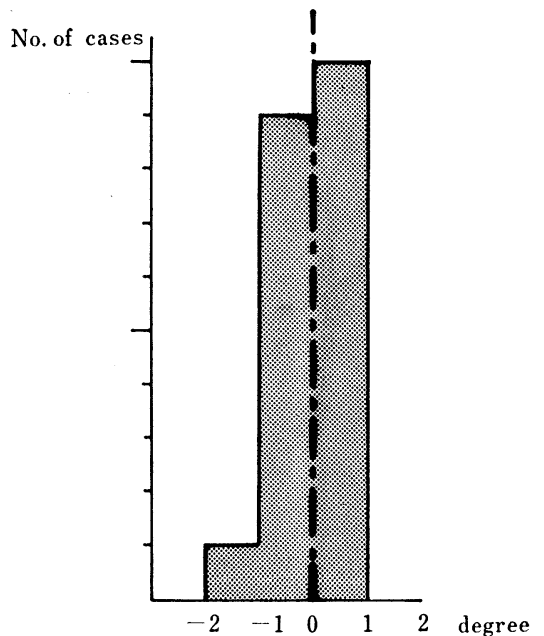

Fig. 4 A histogram of the SNA after treatment

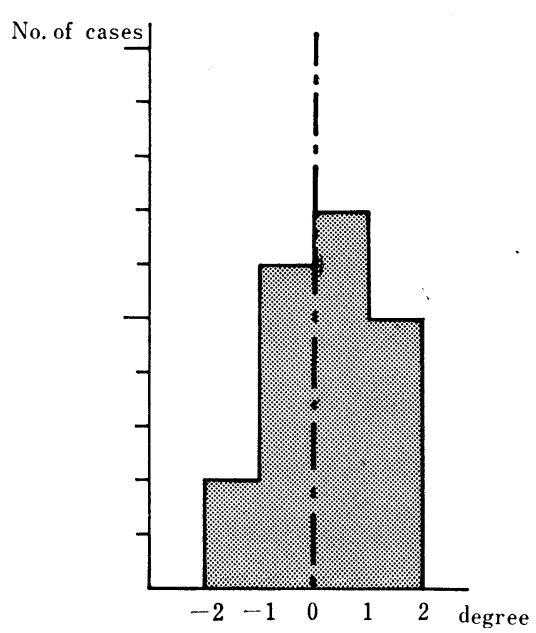

Fig. 5 A histogram of the SNB after treatment

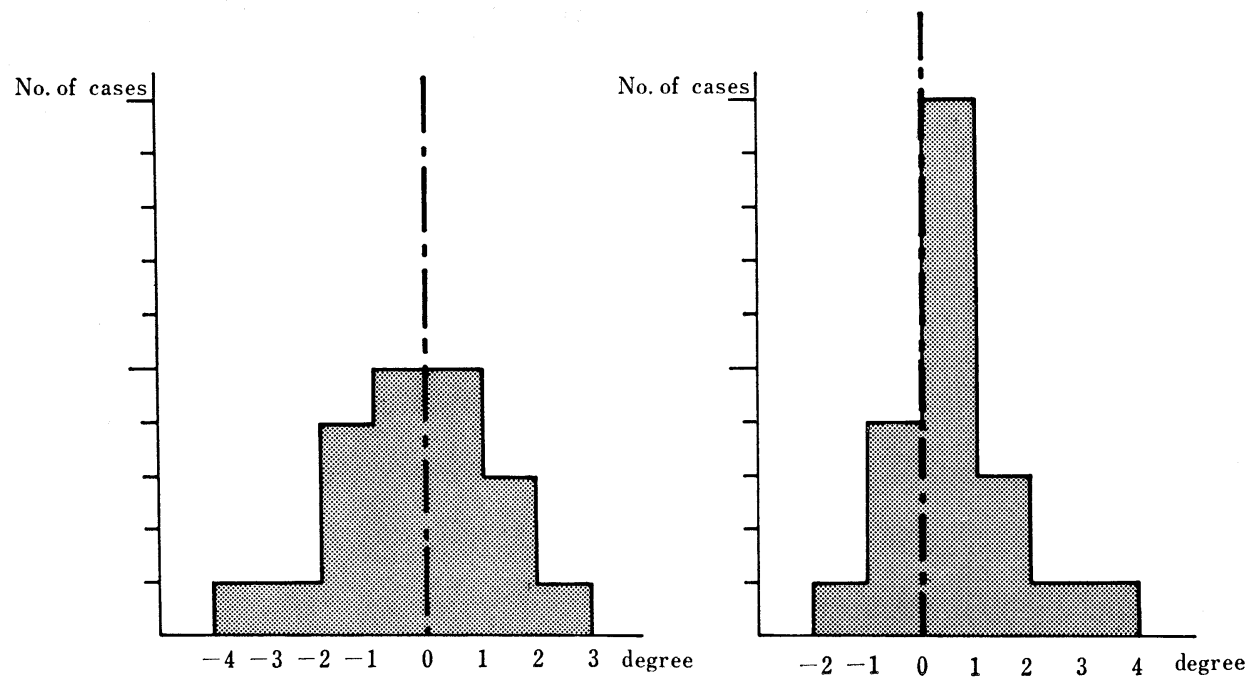

Fig. 6 A histogram of the ANB after treatment

Fig. 7 A histogram of facial angle change after treatment

$54.96^{\circ}( \pm 3.19)$, showing no appreciable change in the degree of protrusion of the mentum. With individual cases, however, as indicated by the histograms, which show post-treatment changes in the facial angle (Fig. 7), 14 out of the 20 cases under study showed no obvious change, 5 cases showed evidence of an increase and in one case a decrease was observed.

The facial angle has a natural tendency to be large in upper protrusion cases 
and small in cases of mandibular distal occlusion and stenosis of the mandible. The facial angle in upper protrusion cases is said to show a tendency to be small when compared with that of normal occlusal subjects. This results in some recession of the mandible and in these cases it is desirable for the facial angle to increase after

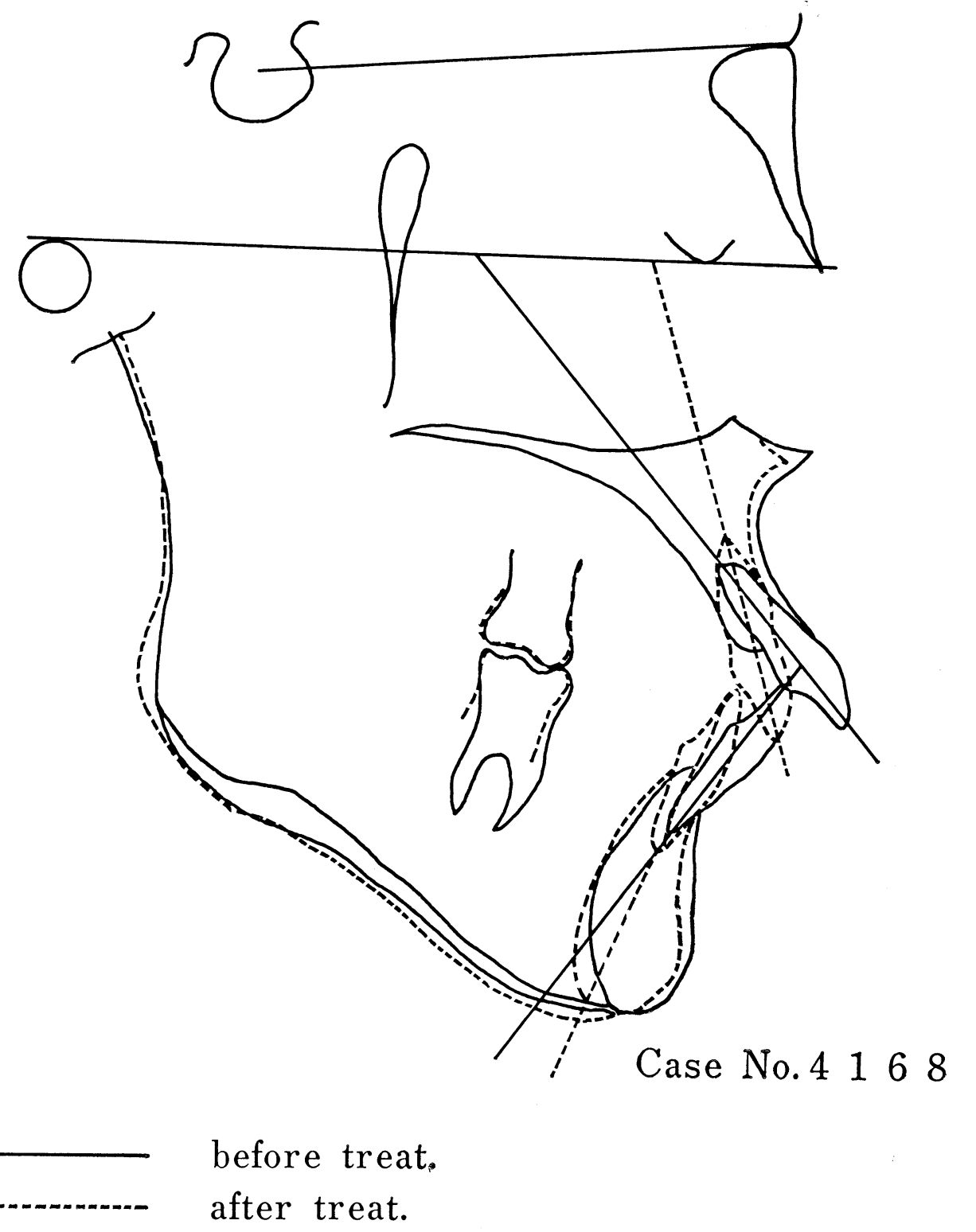

Fig. 8 A case in which a decrease took place in the angle of convexity 
orthodontic treatment. In the 5 favorable cases orthodontic treatment obviously succeeded in accomplishing an anterior movement of the mandible or pogonion.

SAKAмото[14] is of the opinion that, even after age 13, some growth takes place in the mental region though to a slight extent. Generally, however, it is believed that growth comes to an end by age 18. The author is thus led to believe that the orthodontic treatment administered to the cases under study is responsible for the changes in the facial angle.

\section{Convexity}

The mean value before treatment was $7.56^{\circ}( \pm 5.25)$ and after treatment it was $6.36^{\circ}( \pm 6.69)$, showing no marked change in the angle of upper protrusion. The decrease of $1.20^{\circ}$, however, suggests that orthodontic treatment was performed effectively, bringing the upper protrusion back to nearly normal. Out of the 20 cases under study decreases took place in 12 and increases in 7 . The remaining 1 case showed no change at all. Fig. 8 shows a case in which there was a decrease in the degree of convexity and a desirable profile was thus achieved.

To sum up, no remarkable changes were observed in the mean values of SNA, SNB, ANB, the facial angle or convexity before and after treatment. A number of individual cases did show some changes in SNB, ANB, the facial angle and convexity which may have resulted from a movement of the mandible. The author is, therefore, led to believe that they do not affect the skeletal pattern.

(2) Changes in denture pattern

\section{1. $\mathrm{FH}$ to 1}

This angle, which indicates the degree of protrusion of the maxillary central incisors, showed a mean value of $121.50^{\circ}( \pm 7.38)$ before and $104.35^{\circ}( \pm 9.40)$ after

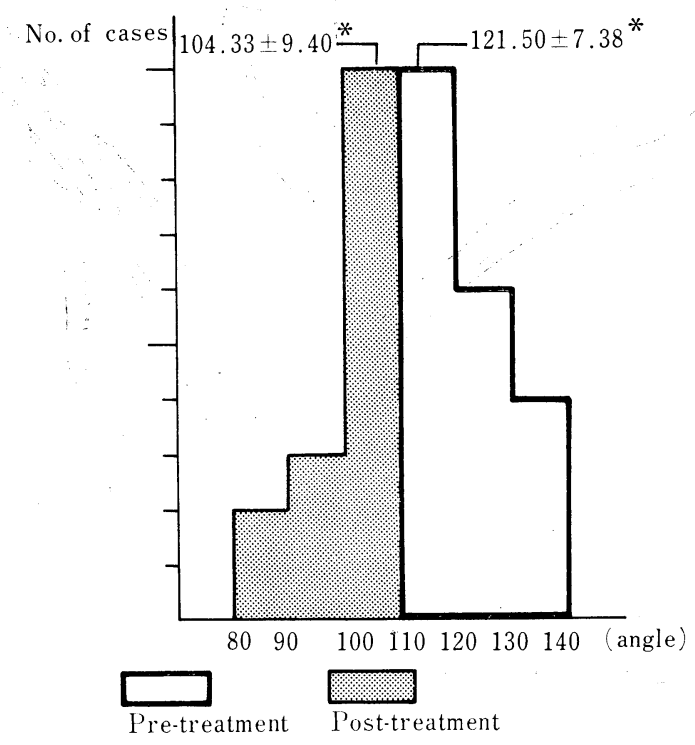

Fig. 9 A histogram of change in the $\mathrm{FH}$ to 1 
treatment, displaying a prominent change (Fig. 9). In normal subjects the mean value was $111.13^{\circ}( \pm 5.54)$ (Table 2$)$.

Cases which gave smaller post-treatment values, less than 1 S.D., as compared with those of normal subjects, may be due to an insufficient lingual root torque or insufficient forward movement of the mandible in treating overjet, hence a forced retraction of the maxillary anteriors. In his study of so-called "Beautiful Faces" of Japanese adult females, YAmANOUCHI[16] gave the value of $106.35^{\circ}( \pm 6.25)$, approximately the same as the post-treatment value in the present study. From these facts, it can be said that despite some unsatisfactory results from orthodontic treatment it proved favorable when regarded in terms of profile improvements.

2. 1 to $\overline{1}$ (interincisal angle)

The interincisal angle, which indicates the angle of inclination between the maxillary and mandibular central incisors, is greatly influenced by a correlation between the FH to 1 and the mandibular to $\overline{1}$. Therefore, there are cases in which a decrease in the $\mathrm{FH}$ to 1 causes an increase in the 1 to $\overline{1}$. In some cases an increase in the mandibular to 1 results in a decrease in the 1 to $\overline{1}$. In other cases no change was present in the 1 to $\overline{1}$ through a mutual compensation of changes in the $\mathrm{FH}$ to 1 and the mandibular to $\overline{1}$.

In the treatment of upper protrusion cases an increase in this interincisal angle

* indicates mean values before and after treatment.

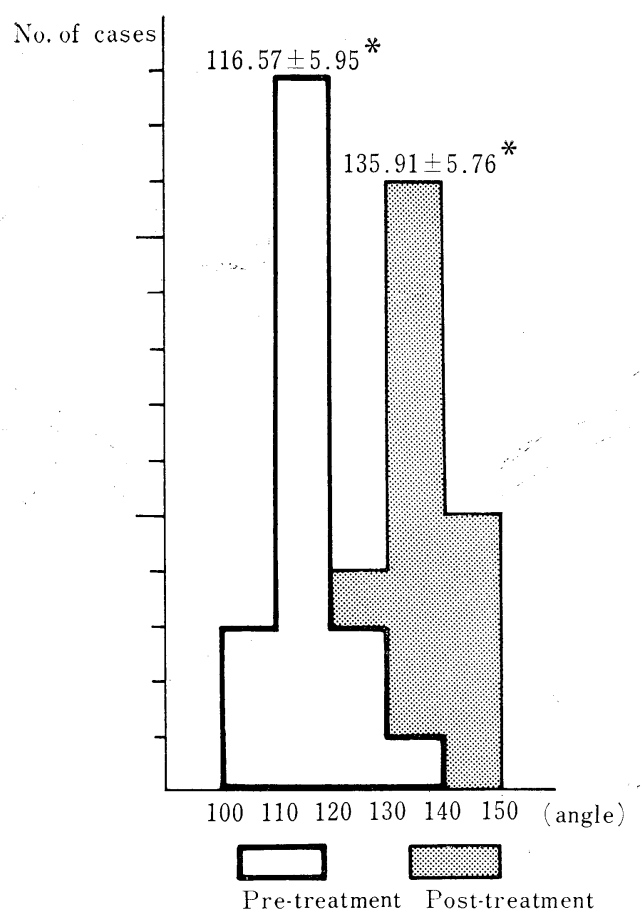

Fig. 10 A histogram giving changes in the 1 to $\overline{1}$ 
is undoubtedly desirable. Within the scope of this study the post-treatment value was increased to $135.91^{\circ}( \pm 5.76)$ as compared with the pre-treatment value of $116.57^{\circ}( \pm 5.95)$, far exceeding the mean normal value of $124.09^{\circ}( \pm 7.63)[13]$. These results brought about by orthodontic treatment (Table 3, Fig. 10) contributed to a reduced impression of upper protrusion. One such example is shown in Fig. 11. The normal maximum value as reported by IIzUKA and IsHIKAwA[13] is $139.40^{\circ}$ and, therefore, it is noteworthy that 5 out of the 20 cases under study gave much larger values than this. It is also to be noted that an extreme improvement in this

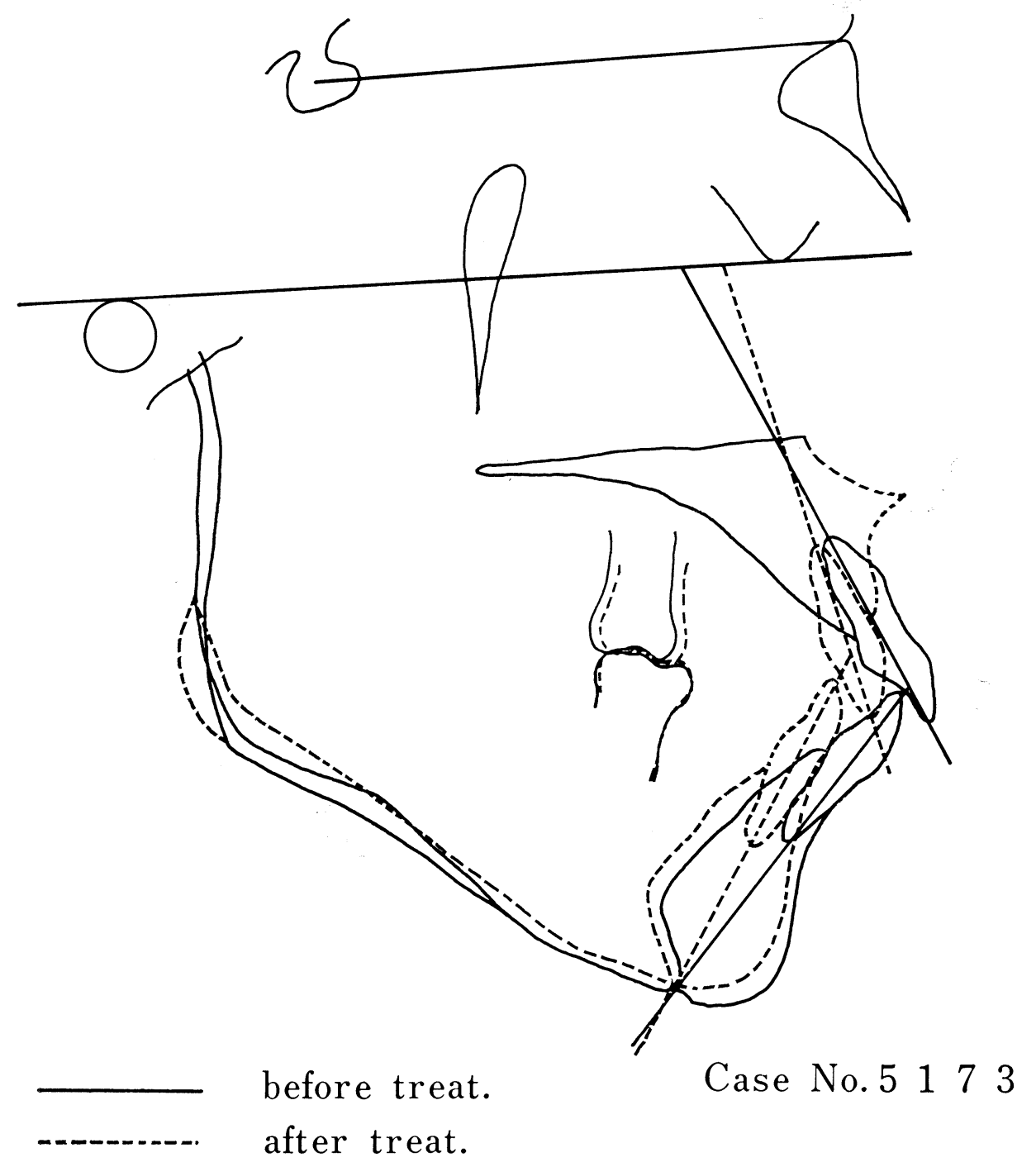

Fig. 11 Changes in interincisal relationships 


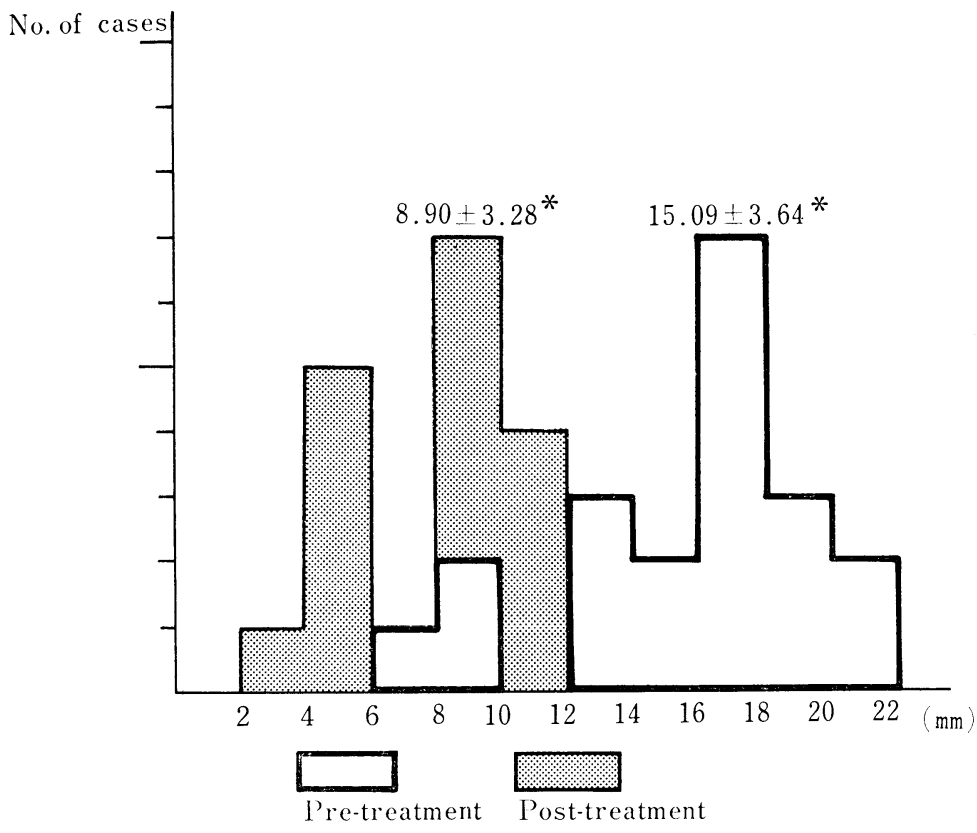

Fig. 12 A histogram of changes in the NP to 1

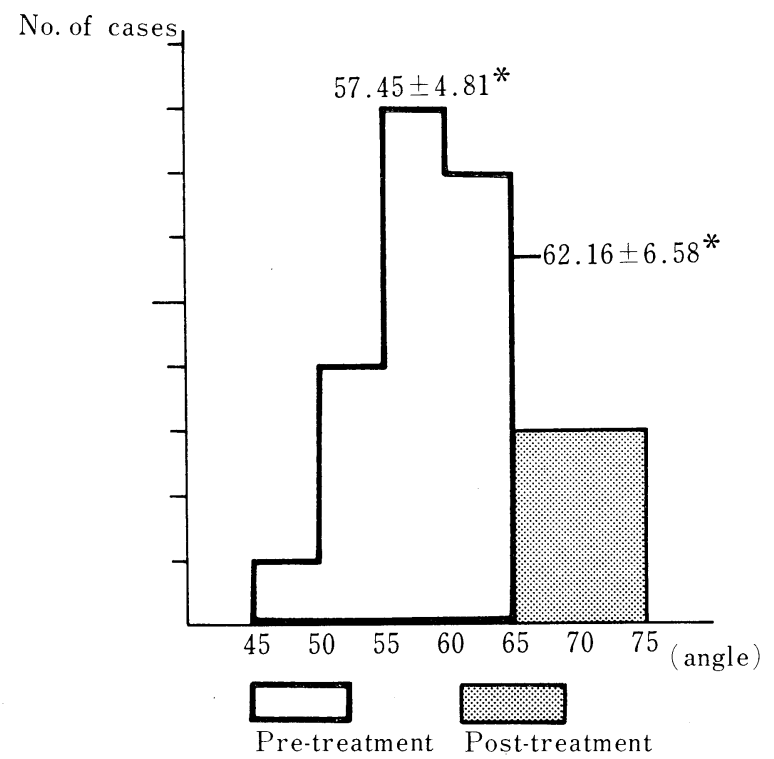

Fig. 13 A histogram of changes in the FMIA 


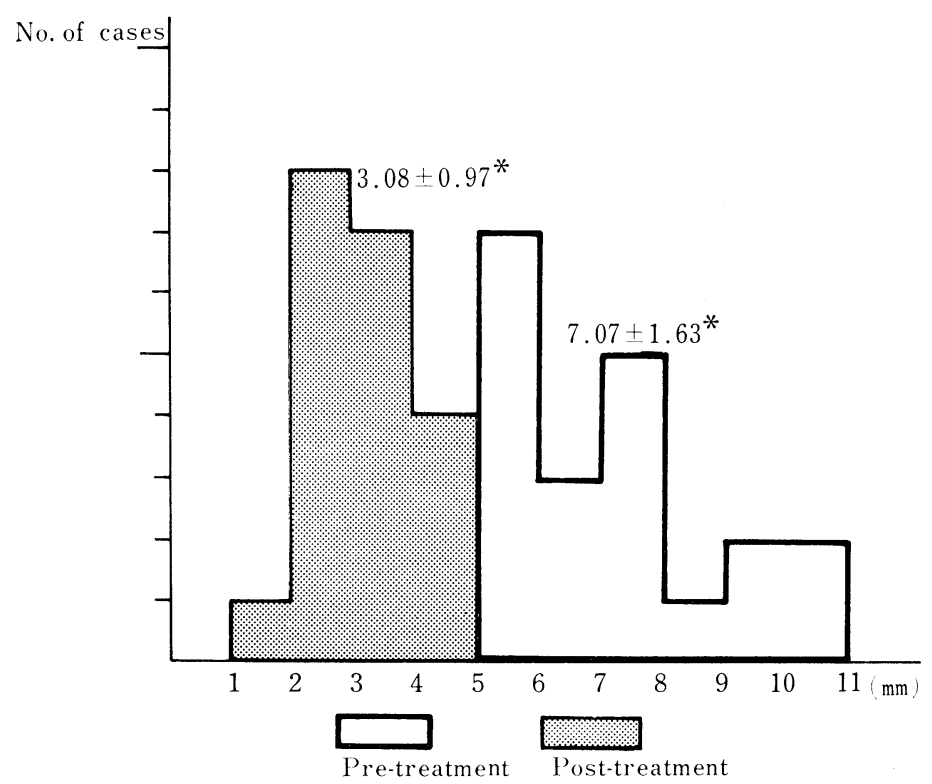

Fig. 14 A histogram of changes in overjet

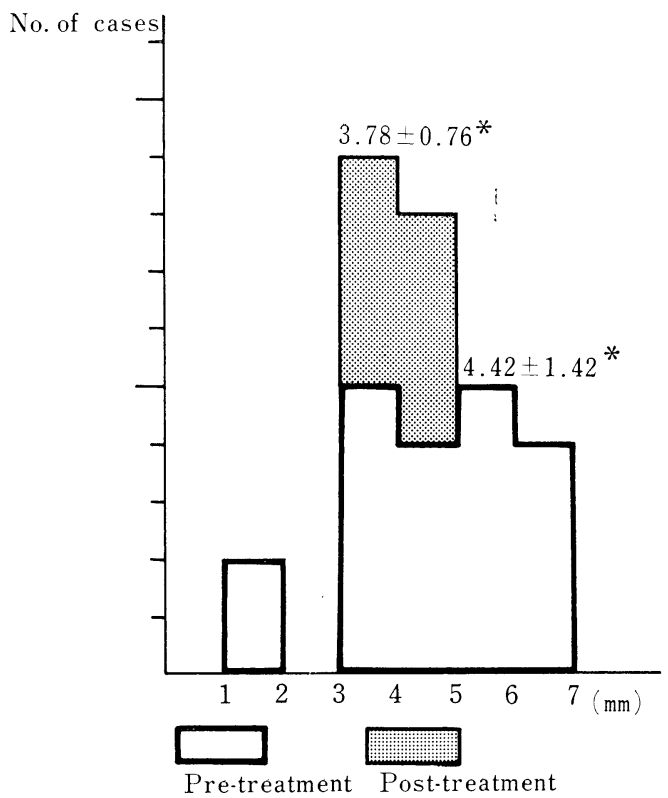

Fig. 15 A histogram of changes in overbite 
angle through orthodontic treatment may exert an influence on an esthetic determination of facial features.

3. NP to 1

The values of this distance, indicative of the degree of protrusion of the maxillary anterior teeth, were $11.74 \mathrm{~mm}( \pm 2.73)$ in normal occlusal subjedts, $15.09 \mathrm{~mm}$ $( \pm 3.64)$ before treatment and $8.90 \mathrm{~mm}( \pm 3.28)$ after treatment, showing a recession of an average of $6.19 \mathrm{~mm}$ in the maxillary anterior teeth (Table 4, Fig. 12).

These findings attest to the fact that, even without changes in the skeletal pattern, lingual movement of the maxillary anteriors, that is, a reduction in the NP to 1 and pronounced changes in the $\mathrm{FH}$ to 1 and overjet, contribute significantly to an elimination of the impression of upper protrusion.

4. FMIA

In treating upper protrusion cases accompanied with labial inclination of the mandibular anteriors a reduction of the $\mathrm{FH}$ to 1 as well as the mandibular to 1 relationship is prerequisite. For this reason an increase in the FMIA is desirable. In the present study, as shown in Table 1 and Fig. 13, an increase of $4.71^{\circ}$ was observed between the pre-treatment value of $57.45^{\circ}( \pm 4.81)$ and the post-treatment value of $62.16^{\circ}( \pm 6.58)$. In other words, there was a profile improvement in the majority of cases.

5. Overjet

A reduction of overjet is an indispensable factor in the treatment of upper protrusion to eliminate the impression of protrusion. Such reductions were observed in all cases. As shown in Table 5 and Fig. 14, there was a measured reduction of $3.99 \mathrm{~mm}$ between the pre-treatment value of $7.07 \mathrm{~mm}( \pm 1.63)$ and the post-treatment value of $3.08 \mathrm{~mm}( \pm 0.97)$.

6. Overbite

As is generally known, cases of upper protrusion are often associated with an excessive overbite and, therefore, in dealing with these cases an adequate depression of the maxillary anteriors is indispensable. Although this is admittedly true, there are some pronounced labially inclined cases without any appreciable overbite.

Within the scope of the present study a decrease of $0.64 \mathrm{~mm}$ took place between the pre-treatment value of $4.42 \mathrm{~mm}( \pm 1.42)$ and the post-treatment value of 3.78 $\mathrm{mm}( \pm 0.76)$ (Table 5, Fig. 15). Individually, 17 out of the 20 cases under study showed a decrease, one case had no change and only 2 cases showed an increase. These 2 cases were ones which showed signs of a pronounced labial inclination of the maxillary anteriors with no excessive overbite.

Summing up, the post-treatment values of FH to 1,1 to 1 , NP to 1 , FMIA, overjet and overbite showed pronounced changes as compared with their pre-treatment values. These changes were particularly marked in FH to 1, NP to 1 and 1 to $\overline{1}$, giving rise to a recession of the maxillary anteriors. The author believes that the effects of orthodontic treatment were fully demonstrated.

\section{Conclusions}

In the present study 20 adult females of Angle Class II Division 1 with an overjet of more than $5 \mathrm{~mm}$ were treated by the edgewise method and examined in pre- 
and post-treatment conditions for comparative purposes. As a result, the following conclusions were reached:

1. There were no appreciable changes in the skeletal pattern before and after orthodontic treatment.

2. Changes in denture pattern were particularly pronounced in the FH to 1 , 1 to $\overline{1}$ (angle), NP to 1 and overjet (distance).

3. From these findings the author has acquired some appropriate knowledge and criteria for evaluating the effects of orthodontic treatment required for adult patients with conditions similar to the group of patients in the present study.

(A summary of this paper was presented before the 1978 annual meeting of the Nihon University Dental Association held in December.)

In closing this paper I sincerely wish to express my appreciation to Prof. Masatoshi ArITA for his most precious guidance. I am also indebted to Asst. Prof. Keisuke NumATA and Lect. Masatoshi NAKAGUKI for their kind assistance and advice.

\section{References}

[1] Fukada, H. 1969. Oral pediatrics, published by Kanehara Publishing Co., Tokyo, pp. 126-128.

[2] Fukuhara, T. 1978. Fundamentals and a clinical study of a cleft palate-Orthodontic treatment, J. J. Orthod. Soc., 37, 161-186.

[3] Kajikawa, Y., Hirose, T., Nakajima, T., Tsuneba, N. and Hanada, K. 1978. Surgical orthodontic treatment for mandibular protrusion (skeletal Class III malocclusion); On body ostectomies including 2 cases of curved oblique ostectomy and sliding ostectomy, J. J. Oral Surg. Soc., 24(2), 348-361.

[4] Takahashi, S., Shigematsu, T., Saito, T., Ko, K. and Tashiro, N. 1980. Ostectomy for abnormal growth of the anterior alveolar portion of the mandible, J. J. Oral Surg., 26(2), 378-385.

[5] Tacogna, N. 1976. A cephalometric analysis of thirty-six skeletal Class II Division I malocclusions in postgrowth females to determine occurrence and frequency of twenty-one dental and skeletal changes due to orthodontic therapy, Amer. J. Orthod., 70(2), 222-223.

[6] Melson, B. 1957. Palatal growth studied on human autopsy material, Amer. J. Orthod., 68, 53.

[7] Miura, F., Sakamoto, T., Irie, M. 1961. Effects of functional orthodontic therapy on upper protrusion-A study by cephalograms, J. J. Orthod. Soc., 20(1), 114-120.

[8] Sone, S. 1968. Cephalometric examinations of upper protrusion cases treated by Begg's method, J. J. Orthod. Soc., 27(1), 46-74.

[9] AsAI, Y. 1972. On changes in the gnatho-facial growth in later adolescent period after 17 years of age, J. J. Orthod. Soc., 31(2), 476-477.

[10] Downs, W. B. 1948. Variation in facial relationships, their significance in treatment and prognosis, Amer. J. Orthod., 46, 1-23.

[11] Graber, T. M. 1942. New horizons in case analysis-clinical cephalometrics, Amer. J. Orthod., 38, 603-624.

[12] Graber, T. M. 1954. A critical review of clinical cephalometric radiography, Amer. J. Orthod., 40, 1-26.

[13] Graber, T. M. 1966. Postmortems in post-treatment adjustment, Amer. J. Orthod., 52, 351.

[14] Atkinson, S. R. 1967. Time for orthodontic treatment, Amer. J. Orthod., 53, 49.

[15] Tweed, C. H. Jr. 1963. Treatment planning and therapy in the mixed denition, Amer. J. Orthod., 49, 881.

[16] Angle, E. H. 1907. Treatment of malocclusion of the teeth, Angles system; S. S. White Mtg. Co., Philadelphia. 
[17] Burstone, C. J. 1963. Process of maturation and growth prediction, Amer. J. Orthod., 49.

[18] Sakamoto, T. 1959. A study on the growth of facial bone in Japanese-based on sella turcica criteria, J. J. Orthod. Soc., 18(1), 1-17.

[19] IIzuka, T. 1958. A cephalometric study on the facial growth in Japanese children, Part I, J. J. Orthod. Soc., 25, 260-272.

[20] Yamanouchi, K. 1959. A study on the so-called beautiful faces in Japanese adult females, Part I, J. J. Orthod. Soc., 18(1), 18-20.

[21] IIzukA, T., IshiKAwA, G. 1957. On the standard values for case analysis by cephalometric radiography, J. J. Orthod. Soc., 16, 4-12. 